\title{
THE HEMODYNAMIC EFFECTS OF HEXAMETHONIUM BROMIDE \\ IN THE DOG, WITH SPECIAL REFERENCE TO \\ "SPLANCHNIC POOLING" 1
}

\author{
By B. COMBES, ${ }^{2}$ J. R. K. PREEDY, ${ }^{3}$ H. O. WHEELER, ${ }^{4}$ R. M. HAYS, ${ }^{5}$ AND \\ S. E. BRADLEY \\ (From the Department of Medicine, Columbia University College of Physicians and Surgeons \\ and the Presbyterian Hospital, New York, N. Y.)
}

(Submitted for publication January 9, 1957; accepted February 21, 1957)

Arterial hypotension develops during the action of hexamethonium in man and the dog because cardiac output decreases in association with a fall in peripheral and central venous pressures (1-5). The drug does induce vasodilation in the skin, muscle, and brain; but vasoconstriction occurs in other areas so that the net total peripheral vascular resistance remains unchanged or actually rises. Since there is little evidence of myocardial dysfunction, diminished venous return of blood to the heart must be implicated as the cause for the fall in output. This response may be attributed 1) to a slight but widespread change in venous tone that results in a generalized retardation in venous flow, 2) to local "pooling" of blood in venous reservoirs or 3) to both. The increased distensibility of the digital veins in human subjects following intravenous administration of hexamethonium (6) gives some support to the first possibility, but the digital vasculature is highly specialized and may not faithfully reflect changes elsewhere. Moreover, a larger quantity of blood is held in other parts of the venous system where even limited changes in tone might be expected to have a correspondingly greater effect upon venous pressure and return. The splanchnic venous bed is particularly important in this respect because it accommodates as much as 20 per cent of the total blood volume at rest in both man and dog. Although hexamethonium does not seem to affect

\footnotetext{
1 This work was supported by a grant from the New York Heart Association.

2 Post-doctoral Research Fellow, U. S. Public Health Service 1953-1955. Present address: Medical Unit, University College Hospital, London, England.

3 Visiting Fellow in Medicine, Fulbright Travel Award 1953-1954. Present address: Medical Unit, The London Hospital, London, England.

4 Life Insurance Medical Research Fund Fellow.

5 Present address : Department of Medicine, Tufts University School of Medicine, Boston, Massachusetts.
}

splanchnic vascular tone since splanchnic blood flow falls in proportion to the fall in arterial pressure $(1,7)$, it is possible that the splanchnic veins are influenced independently of arterioles so that venous distensibility and capacity are altered in the absence of a change in arteriolar resistance. To test this possibility, splanchnic blood flow and splanchnic blood volume were measured by indirect methods in dogs during the fall in cardiac output and arterial pressure produced by hexamethonium.

\section{METHODS}

Thirteen mongrel dogs (10.2 to $17.7 \mathrm{Kg}$.), five of which had been splenectomized at least two weeks previously, were studied under Nembutal ${ }^{\circledR}$ anesthesia $(30 \mathrm{mg}$. per $\mathrm{Kg}$.). Catheters were inserted by way of an internal jugular vein into a left hepatic vein and the right heart and left in place throughout the study. Both femoral arteries were cannulated, one for pressure measurement and the other for blood sampling. After control determinations of mean arterial blood pressure, cardiac output, splanchnic blood flow, total blood volume and circulating splanchnic blood volume were obtained, a single dose of hexamethonium bromide $(0.6$ to $0.8 \mathrm{mg}$. hexamethonium ion per $\mathrm{Kg}$.) was given intravenously. All measurements, with the exception of total blood volume, were repeated following stabilization of the arterial pressure at a hypotensive level (60 to 95 millimeters of mercury). The cardiac output was determined approximately 15 to $20 \mathrm{~min}$ utes, and splanchnic blood flow and splanchnic blood volume 20 to 30 minutes after administration of the drug.

Mean arterial blood pressure was either measured directly with a mercury manometer or determined by planimetric integration of pulse wave tracings recorded photographically from a Statham pressure transducer. Cardiac output was measured by the direct Fick method on the basis of values for oxygen consumption (Benedict-Roth spirometer) and oxygen contents [Van Slyke and Neill (8)] of femoral arterial and right ventricular blood sampled simultaneously. Splanchnic blood flow (ESBF) was estimated by Bromsulfalein (BSP) extraction and clearance (9). Plasma volume was measured by dilution of $I^{181}$-labelled human serum albumin (IHSA) and total blood volume calculated using the arterial hematocrit. 


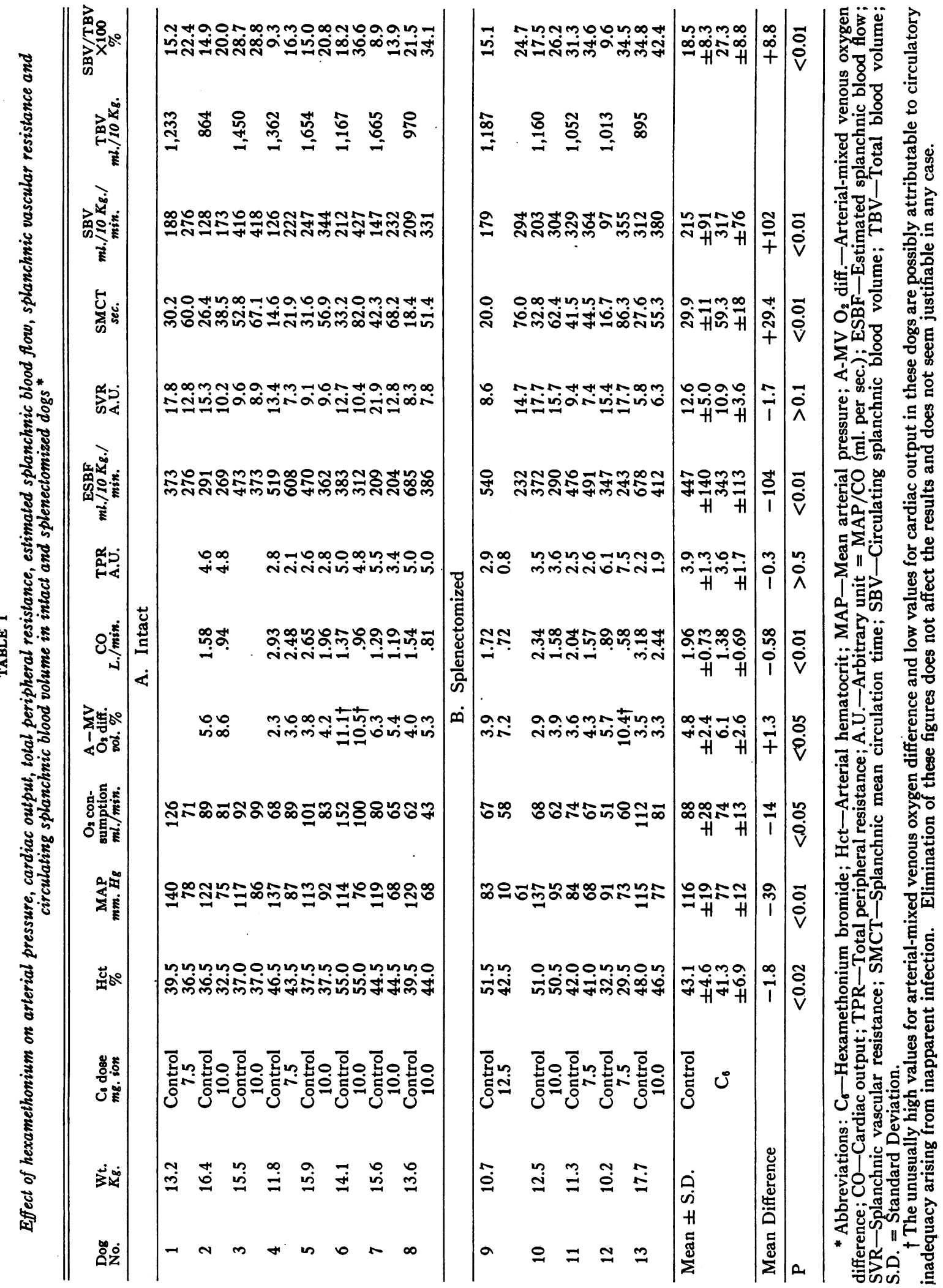


Circulating splanchnic blood volume was determined by the regional dilution technique (10). After rapid injection of approximately 10 to 20 microcuries of IHSA into an external jugular vein, samples of blood were withdrawn simultaneously from the femoral artery and hepatic vein, three times in succession, the first at a slow constant rate of $1 \mathrm{ml}$. per 30 seconds over a period of two minutes, the second and third at a rate of $2 \mathrm{ml}$. per 30 seconds during two succeeding 30-second intervals. Approximately 75 $\mathrm{ml}$. of blood was removed from each animal during the entire study. Aliquots of plasma $(0.5 \mathrm{ml}$.) were pipetted onto aluminum planchettes and dried under an infra-red lamp. A commercial detergent (Haemosol ${ }^{\circledR}$ ) was used to insure even spreading and to prevent sublimation of iodine. Radioactivity was assayed by means of a GeigerMuller end-window tube and conventional scaler. Splanchnic blood volume was calculated by dividing the amount of IHSA activity dispersed in the splanchnic vasculature at equilibrium by the equilibrium concentration as follows:

$$
\mathrm{SBV}=\frac{(\overline{\mathrm{A}}-\overline{\mathrm{V}}) \cdot \mathrm{t}}{[\mathrm{Eq}]} \times \operatorname{ESPF} \times \frac{1}{1-\text { Hct. }}
$$

SBV = Splanchnic blood volume (ml.)

$\bar{A}=$ Mean arterial plasma activity during equilibration (counts per ml.)

$\overline{\mathbf{v}}=$ Mean hepatic venous plasma activity during equilibration (counts per $\mathrm{ml}$.)

$\mathbf{t}=$ Equilibration time in seconds

$\mathrm{ESPF}=$ Splanchnic plasma flow (ml. per sec.)

$[\mathrm{Eq}]=$ Plasma activity at equilibrium (counts per $\mathrm{ml}$.)

Hct. = Arterial hematocrit

When equilibrium (or agreement between radioactivity in the arterial and hepatic venous samples within the analytical error) was achieved in the second sampling period, mean arterial activity was calculated as follows: $\bar{A}=\left(A_{1} \times t_{1}\right)+\left(A_{2} \times t_{2}\right) \div t_{1}+t_{2}$ where $A_{1}$ and $A_{2}$ are the activities of the first and second samples, respectively, and $t_{1}$ and $t_{2}$ are the respective time intervals

TABLE II

Effect of hexamethonium on mean arterial, splenic venous, wedged hepatic venous and right auricular pressures in dogs *

\begin{tabular}{|c|c|c|c|c|c|}
\hline $\begin{array}{l}\text { Dog } \\
\text { No. }\end{array}$ & & $\underset{m m . H g}{\text { MAP }}$ & $\begin{array}{c}\text { Splenic } \\
\text { venous } \\
\text { pressure } \\
\mathbf{m m . H g}\end{array}$ & $\begin{array}{l}\text { Wedged } \\
\text { hepatic } \\
\text { venous } \\
\text { pressure } \\
\text { mm. Hg }\end{array}$ & $\begin{array}{c}\text { Right } \\
\text { auricular } \\
\text { pressure } \\
\text { mm. Hg }\end{array}$ \\
\hline 14 & $\underset{C_{6}}{\text { Control }}$ & $\begin{array}{r}127 \\
85\end{array}$ & $\begin{array}{l}8.0 \\
8.5\end{array}$ & $\begin{array}{l}8.9 \\
7.9\end{array}$ & $\begin{array}{l}1.3 \\
2.0\end{array}$ \\
\hline 15 & $\underset{C_{6}}{\text { Control }}$ & $\begin{array}{r}128 \\
92\end{array}$ & $\begin{array}{r}12.4 \\
7.9\end{array}$ & $\begin{array}{l}8.5 \\
7.7\end{array}$ & $\begin{array}{l}1.6 \\
1.7\end{array}$ \\
\hline 16 & $\underset{C_{6}}{\text { Control }}$ & $\begin{array}{r}120 \\
90\end{array}$ & $\begin{array}{r}11.8 \\
9.4\end{array}$ & $\begin{array}{l}8.4 \\
8.3\end{array}$ & $\begin{array}{l}3.2 \\
3.4\end{array}$ \\
\hline 17 & $\begin{array}{c}\text { Control } \\
\mathrm{C}_{6}\end{array}$ & $\begin{array}{l}145 \\
109\end{array}$ & $\begin{array}{l}11.6 \\
11.8\end{array}$ & $\begin{array}{l}13.3 \\
12.6\end{array}$ & $\begin{array}{l}-0.4 \\
-4.6\end{array}$ \\
\hline
\end{tabular}

* MAP-Mean Arterial Pressure; $\mathrm{C}_{6}$-Following administration of hexamethonium bromide. during which blood was withdrawn. With equilibrium in the third period, the values for $A$ and $t$ for that sample were also incorporated in the calculations. The values for mean hepatic venous activity $(\overline{\mathrm{V}})$ were computed similarly. Mean splanchnic circulation time was calculated from the values for SBV and ESPF. In four additional anesthetized dogs $(9.1$ to $15.9 \mathrm{Kg}$.) pressure tracings (Statham pressure transducer) were obtained successively (within 30 seconds) from the right atrium, an occluded hepatic vein $(11,12)$, the portal vein, and femoral artery, before and after administration of hexamethonium ( 0.6 to $0.8 \mathrm{mg}$. ion per $\mathrm{Kg}$.). Portal venous pressures were measured by means of a polyethylene catheter passed after laparotomy through one of the splenic vein radicles approximately $10 \mathrm{~cm}$. towards the portal vein. All values for venous pressure were measured from a zero reference point located halfway between the dog's back and xiphoid process.

\section{RESULTS}

Comparison of the results obtained in splenectomized and intact dogs failed to show statistically significant differences with the exception of the control mean arterial blood pressure which was significantly lower on the average in the splenectomized animals $(102 \mathrm{~mm} . \mathrm{Hg})(\mathrm{p}=0.02)$ than in the intact dogs $(125 \mathrm{~mm}$. $\mathrm{Hg})$. Consequently, the data for all the animals have been combined, and the mean figures, differences between means, and significance of the differences for the group as a whole are presented in Table I.

\section{Arterial and venous pressures}

The values for mean arterial blood pressures (MAP) presented in Table I are those obtained at or close to the time of measurement of splanchnic blood flow and cardiac output. The pressures were identical at the time of both measurements throughout each study, save in Dog 9, in which the value was $61 \mathrm{~mm}$. $\mathrm{Hg}$ during the determination of splanchnic blood flow and $10 \mathrm{~mm} . \mathrm{Hg}$ during the measurement of cardiac output following administration of hexamethonium. Mean arterial pressure fell in all dogs by $39 \mathrm{~mm}$. $\mathrm{Hg}$ on the average $(p<0.01)$ or 34 per cent. Right atrial, wedged hepatic venous and splenic (or portal) venous pressures did not change significantly (Table II-four animals only).

\section{Cardiac output (CO-Table I)}

Cardiac output fell in the 11 dogs in which the measurement could be made. The fall was associated with a decrease in total oxygen consump- 
tion (by $14 \mathrm{ml}$. per min. on the average, $\mathrm{p}<$ 0.05 ) and an increase in arteriovenous oxygen difference (by $1.3 \mathrm{ml}$. per cent on the average, $p<0.05)$. The average decrease of 0.58 liters per minute (or 30 per cent) was statistically significant $(\mathrm{p}<0.01)$.

\section{Total peripheral resistance (TPR-Table I)}

Total peripheral resistance was calculated in arbitrary units (A. U.) by dividing the mean arterial blood pressure by the cardiac output in $\mathrm{ml}$. per second. Total peripheral resistance did not change on the average $(p>0.5)$ since cardiac output and mean arterial blood pressure decreased to approximately the same extent. It is possible that the marked reduction in TPR which was observed in Dog 9 may be accounted for at least in part by the failure to obtain a value for mean arterial pressure at precisely the time of the measurement of cardiac output.

\section{Estimated splanchnic blood flow and resistance (ESBF and SVR-Table I)}

Splanchnic blood flow decreased in 10 dogs, remained unchanged in one (Dog 7), and rose in two (Dogs 4 and 11). The average decrease in ESBF per $10 \mathrm{Kg}$. body weight was $104 \mathrm{ml}$. per min., a significant reduction $(p<0.01)$. The splanchnic vascular resistance (SVR-Table I) was computed in arbitrary units (A. U.) by dividing the mean arterial pressure by the splanchnic blood flow (ml. per second). Splanchnic resistance decreased in 7 dogs (Dogs 1, 2, 4, 6, 7, 10 and 11), increased in 2 (Dogs 9 and 12) and remained unchanged in 4 (Dogs $3,5,8$ and 13). The average reduction in resistance $(1.7 \mathrm{~A}$. U.) was not statistically significant $(p>0.1)$.

\section{Splanchnic blood volume (SBV-Table I)}

Splanchnic blood volume averaged $215 \mathrm{ml}$. per $10 \mathrm{Kg}$. body weight during the control periods, amounting to 18.5 per cent of the total blood volume (SBV/TBV-Table I). After hexamethonium, SBV increased in 12 dogs and remained unchanged in one (Dog 3$)$. The average increment of $102 \mathrm{ml}$. per $10 \mathrm{Kg}$. body weight (48 per cent) was highly significant $(p<0.01)$. This change was reflected in an increase in the mean splanchnic circulation time (SMCT-Table I) from 29.9 seconds on the average during the control periods to 59.3 seconds following hexamethonium ( $\mathrm{p}<$ 0.01 ). The tendency for the hematocrit to fall (Hct.-Table I) could be explained largely on the basis of the withdrawal of blood samples, and it was therefore assumed that total blood volume remained unchanged. On this assumption, the splanchnic vasculature appeared to contain 27.3 per cent of the blood volume during the hypotensive phase.

\section{DISCUSSION}

Autonomic blockade following the intravenous administration of hexamethonium produced a fall in blood pressure in dogs that could be ascribed solely to a reduction in cardiac output, in agreement with the results of other workers (1-4). The splanchnic blood flow tended to decrease in proportion to arterial pressure, whereas circulating splanchnic blood volume appeared to rise. The seemingly paradoxical expansion of the splanchnic bed to accommodate a larger volume of blood without significant simultaneous vasodilatation to permit a relatively larger minute flow could be construed as evidence that hexamethonium reduces splanchnic venous tone without affecting the arterioles. Retarded venous return as a result of "pooling" in the splanchnic reservoir-and presumably also in veins elsewhere in the bodycould therefore play an independent role in reducing cardiac output and arterial pressure. Further analysis of the data, however, does not sustain the validity of these inferences nor of the conclusion to which they tend-that the major site of action of hexamethonium lies upon the venous side of the circulation.

As a matter of fact, interference with arteriolar activity by hexamethonium is evident in the absence of the usual change (13) in the peripheral vascular resistance during the development of arterial hypotension. The tendency for maintenance of arteriolar cross-section by so-called "basal tone" (14) in vascular beds that have been completely denervated by surgical methods may account for the apparent absence of peripheral arteriolar vasodilation. The difference between the arteriolar and venous responses may actually reflect differences in the distending forces exerted by intraluminal pressures which are inversely related to di- 
ameter and are consequently much more powerful in the veins than in the arterioles and capillaries. In this view, the splanchnic arterioles and veins are more or less equally affected by hexametho,nium; but in the latter the "basal tone" [as defined by Folkow (14)] is not sufficient to resist distention.

The anatomic evidence (15) suggests that the hepatic and portal venous systems contain the bulk of the circulating blood in the splanchnic bed. If the splanchnic vascular reservoir simply serves as a passive elastic receptacle, its volume would be a function of the distending pressure alone. The fact that SBV increased without change (or with a fall) in the portal venous pressure seems to point to an active role of the venous musculature in determining capacity. Splanchnic blood flow and splanchnic venous pressures decrease similarly in dogs following hemorrhage, but with a reduction, rather than an increase, in circulating splanchnic blood volume (16). The quantity of blood within the splanchnic vasculature therefore appears to vary independently of local pressure differences and blood flow. It seems reasonable to conclude that change in capacity is determined largely by an active dimensional change presumably arising from contraction or relaxation of the smooth muscles in the walls of hepatic and portal venous radicles under the control of the autonomic nervous system.

Estimation of the splanchnic blood volume by the regional dilution technique requires the assumption that $\mathrm{I}^{131}$-labelled human serum albumin is evenly dispersed throughout the bed during an equilibration period of a minute or less. The tracer has little time to find its way into blood not actively a part of the circulating volume and the blood in the splenic pulp is thus not readily accessible to measurement. The change observed following administration of hexamethonium was therefore the same in intact and splenectomized animals.

Owing to the uncertainties regarding the relationships between venous and atrial pressures and cardiac output, it is difficult to evaluate the cardiac effect of hexamethonium or to define with precision the part played by "splanchnic pooling." Unfortunately, the methods currently available are too crude to permit quantitative appraisal of the course of events during the brief interval required for circulatory adjustment. When measurements could be made, a quasi steady-state had developed in which cardiac output was persistently depressed in association with a right atrial pressure which had apparently been stabilized at the control level. Changes in pressure too small for measurement may have been implicated as the basis for the continued reduction in output, but the possibility that hexamethonium actually interfered with cardiac function cannot be eliminated.

\section{SUMMARY}

The systemic and splanchnic hemodynamic effects of hexamethonium ( 0.6 to $0.8 \mathrm{mg}$. hexamethonium ion per $\mathrm{Kg}$. body weight) were studied in thirteen anesthetized dogs-in five at least two weeks following splenectomy. Cardiac output was measured in 11 dogs by the direct Fick method, splanchnic blood flow by the Bromsulfalein method, and the circulating splanchnic blood volume by the regional dilution technique. Femoral arterial, right atrial, wedged hepatic venous, and portal venous pressures were measured directly in four animals.

Arterial pressure decreased in all the animals, by $39 \mathrm{~mm}$. $\mathrm{Hg}$ on the average; whereas atrial, hepatic venous, and portal venous pressures did not change. Cardiac output fell, by 30 per cent on the average, to approximately the same extent as the arterial pressure. Estimated splanchnic blood flow decreased in 10 dogs, remained unchanged in one and rose in two; on the average falling significantly ( $p<0.01$ ) by $104 \mathrm{ml}$. per min. per Kg. Splanchnic vascular resistance was not significantly affected on the average, but the circulating splanchnic blood volume increased in twelve dogs and remained unchanged in one, rising on the average by $102 \mathrm{ml}$. per $10 \mathrm{Kg}$. body weight or 48 per cent.

These findings may be interpreted as evidence for the view that autonomic blockade by hexamethonium causes a fall in arterial pressure by simultaneously reducing cardiac output and interfering with compensatory peripheral arteriolar adjustments. The fall in cardiac output may be attributed to a decrease in venous return as a result, in part at least, of "pooling" in the splanchnic vasculature secondary to diminished venous "tone." Autonomic blockade therefore appears to affect both arteriolar and venous activity. 


\section{ACKNOWLEDGMENT}

We wish to express our gratitude to Mrs. Phyllis Richardson, Mrs. Barbara Bauer, and Miss Marion Yulinsky for technical assistance.

\section{REFERENCES}

1. Freis, E. D., Rose, J. C., Partenope, E. A., Higgins, T. F., Kelly, R. T., Schnaper, H. W., and Johnson, R. L., The hemodynamic effects of hypotensive drugs in man. III. Hexamethonium. J. Clin. Invest., 1953, 32, 1285.

2. Werkö, L., Frisk, A. R., Wade, G., and Eliasch, H., Effect of hexamethonium bromide in arterial hypertension. Lancet, 1951, 2, 470.

3. Crumpton, C. W., Rowe, G. G., O'Brien, G., and Murphy, Q. R., Jr., The effect of hexamethonium bromide upon coronary flow, cardiac work and cardiac efficiency in normotensive and renal hypertensive dogs. Circ. Research, 1954, 2, 79.

4. Grob, D., Scarborough, W. R., Kattus, A. A., Jr., and Langford, H. G., Further observations on the effects of autonomic blocking agents in patients with hypertension. II. Hemodynamic, ballistocardiographic and electrocardiographic effects of hexamethonium and pentamethonium. Circulation, 1953, 8, 352.

5. Burch, R. R., The effects of intravenous hexamethonium on venous pressure of normotensive and hypertensive patients with and without congestive heart failure. Circulation, 1955, 11, 271.

6. Burch, G. E., A method for measuring venous tone in digital veins of intact man. Tr. A. Am. Physicians, 1954, 57, 174.
7. Reynolds, T. B., Paton, A., Freeman, M., Howard, F., and Sherlock, S., The effect of hexamethonium bromide on splanchnic blood flow, oxygen consumption and glucose output in man. J. Clin. Invest., 1953, 32, 793.

8. Van Slyke, D. D., and Neill, J. M., The determination of gases in blood and other solutions by vacuum extraction and manometric measurement. I. J. Biol. Chem., 1924, 61, 523.

9. Bradley, S. E., Ingelfinger, F. J., Bradley, G. P., and Curry, J. J., The estimation of hepatic blood flow in man. J. Clin. Invest., 1945, 24, 890.

10. Bradley, S. E., Marks, P. A., Reynell, P. C., and Meltzer, J., The circulating splanchnic blood volume in dog and man. Tr. A. Am. Physicians, 1953, 56, 294.

11. Friedman, E. W., and Weiner, R. S., Estimation of hepatic sinusoid pressure by means of venous catheters and estimation of portal pressure by hepatic vein catheterization. Am. J. Physiol., 1951, 165, 527.

12. Taylor, W. J., and Myers, J. D., Occlusive hepatic venous catheterization in the study of the normal liver, cirrhosis of the liver and noncirrhotic portal hypertension. Circulation, 1956, 13, 368.

13. Wiggers, C. J., Physiology of Shock. New York, The Commonwealth Fund, 1950.

14. Folkow, B., Nervous control of the blood vessels. Physiol. Rev., 1955, 35, 629.

15. Mall, F. P., A study of the structural unit of the liver. Am. J. Anat., 1906, 5, 227.

16. Reynell, P. C., Marks, P. A., Chidsey, C., and Bradley, S. E., Changes in splanchnic blood volume and splanchnic blood flow in dogs after haemorrhage. Clin. Sc., 1955, 14, 407. 